This item was submitted to Loughborough's Research Repository by the author.

Items in Figshare are protected by copyright, with all rights reserved, unless otherwise indicated.

\title{
Workplace dynamics in professional sport: a case study of identification, political skill, and personal control
}

PLEASE CITE THE PUBLISHED VERSION

https://doi.org/10.1123/cssm.2018-0028

PUBLISHER

Human Kinetics

VERSION

AM (Accepted Manuscript)

PUBLISHER STATEMENT

Accepted author manuscript version reprinted, by permission, from Case Studies in Sport Management, 2019, 8 (S1): pp.S28-S32, https://doi.org/10.1123/cssm.2018-0028. (C) Human Kinetics, Inc.

\section{LICENCE}

CC BY-NC-ND 4.0

\section{REPOSITORY RECORD}

Swanson, Steve, and Samuel Todd. 2019. "Workplace Dynamics in Professional Sport: A Case Study of Identification, Political Skill, and Personal Control”. figshare. https://hdl.handle.net/2134/11914506.v1. 


\title{
WORKPLACE DYNAMICS IN PROFESSIONAL SPORT: A CASE STUDY OF IDENTIFICATION, POLITICAL SKILL, AND PERSONAL CONTROL
}

\begin{abstract}
This case is based on a collection of real-life scenarios encountered by employees working for professional sport organizations. The workplace in this environment contains circumstances distinct to the sport context which this case aims to highlight. A small work group of three individuals with diverse backgrounds representing key departments in a professional basketball club are brought together to lead a difficult challenge in the community. Over the course of the season, several meetings and personal interactions play out which present difficulties in productivity due to individual differences in human relations capacity and varying psychological connections with the environment. In combination with the teaching notes, the case is designed to highlight (1) the special nature of employee identification in the professional sport setting (2) an array of political skills which are relevant and useful to the sport workplace and (3) the role of perceived personal control in sport organizations. An overview of theory and its specific application to the case is provided along with discussion questions and answers to aid instructors in effectively engaging with students around the topical areas.
\end{abstract}

Keywords: Organizational identification, team identification, identity, political skill, personal control, organizational behavior, human resource management, sport management 


\section{Fast Forward}

Maria, the Community Relations Assistant and the Director of the Osmington Orca's HOME project, made her way back to her office after another unproductive meeting at the team practice facility. She couldn't stop thinking of the dire consequences if she couldn't start to make some headway with this homeless project. She had been on the job for nearly five months, and had not yet been able to get enough buy-in from her work group to establish a clear direction and make meaningful progress. Maria had initially been excited to work with Lauren, the Director of Marketing, and Omar, Director of Player Programs, but she worried that if she couldn't get them to help her find a way forward, her boss would tell her that things just weren't working out and that they were going to find someone else to fill her position.

\section{Background to the Setting}

The Osmington Orcas are a member of the National Basketball League (NBL) which is at the premier level of the North America sporting landscape. One of the core values of the organization is giving back to the community, and it has been an industry leader in developing corporate social responsibility programs which are cutting edge and address issues at the fiber of the regional area. In recent years, a homeless crisis has emerged as the biggest social issue facing their community, with thousands of homeless people living on the streets of their city. As this crisis has reached critical level in metropolitan area, the Orcas organization has become focused on finding a way to use the power of sport to affect positive change in this challenging aspect of their local society. The crisis has also become extremely relevant at a micro geographical level, as the majority of the homeless population tend to exist in the area of the city where the Orcas' arena is located, and therefore have very visible presence for employees working at the arena and fans attending games. Working with the local municipalities, the Orcas have developed a partnership to fund a new staff position with 
the specific remit to develop a plan of action for how the Orcas organization can best address this issue. There was a strong desire to have the person in post by the beginning in the offseason, with the intention of providing an approximate three-month window to establish a clear organizational direction on this issue during the following season. The primary responsibility for this hire is to facilitate a concrete pathway for the Orcas to make a meaningful difference in this important community issue, but secondary duties in the main community development area would also be expected.

\section{Maria Gets to Work}

Maria’s first day in her new position was in early August. In her interview, she had told her new boss that she was "extremely passionate about addressing the homeless issue in the local region, and sport was a suitable vehicle to assist with such an important community matter." While determining the necessity for this position, the senior leadership team recommended that the new employee should lead a special internal task force called Homeless Orcas Mean Everything (HOME). The name was derived from the perspective that the Orcas should represent the entire community, and therefore consider the homeless population as part of their community family who all need a place to call home. To ensure diversity of thought and representation from key organizational areas, the senior leadership team arranged for two other members of staff to help Maria develop a specific action plan to engage with this societal challenge in the best way possible. In the interest of forming a cross-functional team, and being mindful of the way the Orcas are regarded in the community, the senior leadership team directed the Marketing Director (Lauren), and the Player Programs Director (Omar), to work alongside Maria on the HOME task force.

It was the first week on the job for Maria in the community relations department of the Osmington Orcas of the National Basketball League (NBL). After completing an introduction program with the human resources staff and being formally introduced at an all- 
company meeting earlier in the week, Maria was ready to finally begin working on the (major) project she was hired to lead. While her job duties aligned globally with the wider area of community relations, her main task at this time was to lead the HOME initiative. Maria was excited about the taskforce membership and had called for an initial meeting with the group later that afternoon, which would provide the first opportunity for Maria to meet the group members in person. She was passionate about the cause, but at the same time feeling a bit nervous about making a good first impression and starting off on the right foot with Lauren and Omar.

Throughout the morning, several thoughts rushed through Maria's head: I really wonder how this meeting will go today. These people don't know me, or my style, so we will need to spend a little time learning about each other to get started. I've corresponded productively with Lauren and Omar on email, but having in-person meetings is a little different. I don't want to waste precious staff time, but know it will be hard to jump right in without understanding Lauren and Omar on a personal level. I've checked out their bios online and feel like I know everything I can about them, but you just never know how people really are until you work with them directly. Some of my new colleagues in the community relations office have indicated that Lauren might be somewhat difficult to work with, given the issues she had last year with the marketing fiasco. I'll be sure not to mention that. I can't believe she allowed the Orcas brand to suffer like that when the star player was accused of domestic violence. That was a big problem, or at least that is what I hear at around the water cooler.

Now Omar, from what I'm told is kind of an unknown entity to most people in my area; he doesn't seem to have many friends on the business side of the organization. Maybe he's just private, or maybe just busy, or, maybe he just thinks he's a 'big shot.' But I'm sure he knows a lot of influential people around the league, and I'm eager to work with someone 
on the player ops side of the house. This is a great opportunity for me, I hope I can make a good impression. But I'm scared. This is a high-profile assignment, and it's my first one here. I don't know anyone in the organization, and I'm not at the same level as the others on the taskforce, nor do I have the same institutional or industry knowledge. I need to relax so I don't seem like a "rookie." I'm sure everything will be fine, just be professional and start moving the project forward in the best way you know how.

\section{HOME Task Force's Initial Meeting}

The first official meeting for the HOME Task Force was called for the middle of September. This meeting was scheduled to take place in the Orcas room, one of the nicest meeting rooms in the building, with the walls filled with photos from floor to ceiling of historic moments in Orcas history. Maria was conscious of not being late to her own meeting, so she made sure to leave at the right time. However, as she entered the room Lauren was already sitting at the table with her laptop open and talking to someone who Maria thought might be a member of the senior management team. Darn, she beat me here. Wow, she's very professionally dressed and looks like she means business. Maria confidently entered the room, but it still felt a little awkward as their eyes met while Lauren quickly finished up her call.

“Hi, I'm Lauren Byers, the Marketing Director. You must be Maria. Welcome to the Orcas. I've heard good things about you," Lauren said.

Maria responded with, "Hi, yes I'm Maria, a pleasure to meet you Lauren. Likewise, I've heard great things about you, and I'm really happy you were able to be on the HOME committee with me. Your background and experience will I'm sure be extremely helpful."

After the two had exchanged pleasantries for a few minutes, Omar entered the room dressed in an Orcas track suit and says, "Hi Lauren, good to see you again," and extended his hand for handshake. "You must be Maria. I'm Omar. Great to meet you. Sorry I'm a little 
late. The coach needed to talk to me for a minute just when I was leaving the practice facility to drive over here."

“Hi Omar. Very nice to meet you. No problem, I understand. It's really great to have a member of the basketball staff on the HOME project."

After a few minutes of small talk about the growing traffic problem in the area, Maria wanted to spend time getting to know both Lauren and Omar but was suddenly interrupted by Lauren who said, "Maria, not to run your meeting here, but my schedule is packed today, so can we just get down to business?"

Maria was shocked and little caught off guard. So she quickly opened her laptop, took a sip of coffee, and began with an historical overview of the cause, the assignment, the goal, and how she was hired and charged with leading the mission. After a few minutes, Lauren explained how she's really supportive of the project, and conveyed that she wants to do everything she can to support it, but also said from the start that she'll need to be ultraconscious that the Orcas brand image is in no way tarnished by future activities in this initiative. Omar followed with a short statement of his support, and acknowledged how important of a social issue this was. He then inserted the caveat that he was very busy with player operations matters and sometimes unexpectedly got involved with the immediate personal needs of the players, so his schedule was unpredictable most days. Further, Omar made sure to mention that while most people thought it was easy to get the players to engage with initiatives like this, in reality, their contracts sometimes do not allow for this. So before the taskforce goes too far, it would be important to run ideas by him if they involve players. Although he ended his comments with an offer to call some of his league contacts who have worked on similar community projects and see if he could learn from their experiences.

Maria sensed that Lauren and Omar both had hidden agendas, but at this point, she didn't have a full read on what they were. In the interest of moving the meeting along, she 
decided it would be best to spend 30 minutes brainstorming ideas about how the organization could best help the current homeless status in the community. The conversation really lacked direction, and Maria sensed that the group dynamics were not off to the best start. The issue was not going to be as easy to solve as she originally thought. In fact, in the middle of the ideas, both Lauren and Omar were quick to discuss the need to consider "unintended consequences" of connecting prominent, wealthy people to others who are far less fortunate. And further (and maybe most importantly given the history with Lauren of late), the ramifications of another failed initiative to the Orca's brand. Could this be a recipe for disaster if perceived by the public that the Orcas weren't doing enough? Were there safety or health issues that had yet to be considered for the players? Sensing that she didn't want the meeting to end on a sour note, Maria suggested they regroup in a few weeks' time after thinking a little more.

After the meeting Maria was overwhelmed by the enormity of the situation and felt pretty deflated. I'm not sure what I've gotten myself into here. Both Lauren and Omar seem nice, but it's easy to see how they are definitely coming at this thing from different directions. Lauren really appears to be super protective of her territory, and the way she speaks so matter-of-factly seems to rub Omar (and me) the wrong way. It's like she really is engaged with the idea of making this look right for the organization, but is not much of a fan of the team or tuned-in to their day-to-day situations. Note to self: Lauren knows how to use her influence and isn't afraid of ruffling feathers. And wow, Omar really has his finger on the pulse of the players and their needs/desires. He is passionate about his job, I can tell. His track suit is awesome, and I wish I got to dress like that at work. However, seems like he's overly interested in insulating the players from any unexpected negative outcomes that may result from their involvement with the homeless population, rather than making a contribution to a worthy cause on behalf of the Orcas organization. His tendency to guard 
the players' availability will greatly restrict our use of a major organizational asset, and it may make the franchise seem somewhat disingenuous to the cause. While we were searching for answers, I was grateful for Omar's offer to use his league contacts to get some insight into how they've dealt with other sensitive issues. That seems smart, and I certainly don't have the same level of network. However, I'm also worried about how it might look if we're seen as copying others, rather than developing our own innovative solutions which are most appropriate for our specific community. I don't want the senior leadership of Orcas thinking of me as someone who takes shortcuts with 'google searches' for complex problems. I don't think that meeting gave them the best taste of my capabilities, so I wonder what they are thinking of me now. I didn't want to be confrontational, especially with two well-known figures in the organization, so I ended up just going along with what they said.

\section{HOME Task Force's Second Meeting}

A few weeks after the first meeting, Maria thought it was time to get the taskforce together again, and started emailing Lauren and Omar. It was challenging to find a time that worked; Omar was always in meetings with players, coaches, team representatives, or on the road. Lauren was equally booked. So, out of deference to Omar (and a nice excuse to see the team's practice facility) she asked Omar if they could meet at his office. He accepted. Maria was relieved that this seemed appreciated by Omar, pleased that Lauren had no issues with it, and she secretly was excited to have the opportunity to go to the practice facility for the first time. Maria was mature enough to not get overly excited about potentially seeing any famous Orcas players, although she also had to admit that she was drawn to the idea of being closer to the team. She was also, however, more focused than ever to help the organization move forward on the important HOME initiative.

In between the first and second meetings, Maria had done a great deal of thinking about options to put forward so that she could feel at more of an advantage when debating 
issues with the group. While she was yet to have a preferred direction, she felt far more equipped to consider steps most appropriate for the task force to consider putting forward to the senior management team. One idea that had been recently considered by the city council was to create large tents to provide temporary shelter for the homeless, and wanted to get Lauren and Omar's thoughts on a couple of ways the Orcas could potentially get involved.

While waiting for Omar in the meeting room, Maria said to Lauren, "Did you see last night's game? Boy was it an exciting finish. I'm so amazed at the skill of players, and it's such a great feeling to be a part of big wins like that. The players all seem like really good guys too, and it's pretty cool to learn more about their backgrounds in the short time I've been here."

Lauren responded by saying, 'No I didn't catch last night's game. I decided to watch a movie instead. I really like the marketing aspect of working here, but I'm actually not that into basketball. Even though I know the power of social media to build connections with fans, I think a lot of it is just trivial information that I don't have much interest in personally."

Early in the meeting, Maria brought up a few ideas. "Since we're looking to do something timely and in partnership with the community, I was wondering if we might be able to partner with the city council on their proposed tent initiative for the homeless? For example, we could consider putting our logo on the tents as visual representation of our partnership and commitment to the community. In addition, we could have a few players visit the tents each week during the season to shake hands and hand out food for those in need." After a bit of thinking and serious faces, Lauren broke the silence and said, "I would have concerns with regard to the overall image of the organization. I see how this is wellintentioned, however putting our logo on a tent which could be perceived as representing undesirable circumstances seems too risky to me. I'm also fairly certain that several members 
of the senior management I know would also be very skeptical. I think we need to consider alternatives that wouldn't have this type of associated risk."

Omar followed up by saying, "Yeah, I also don't think it's reasonable to consider such a long-time commitment by the players due to their busy schedules, and most of them have clauses in their contract that restrict the number of appearances they have during the season. Coach is also very sensitive about having enough rest time and keeping their minds right. I'd also have reservations about their own player brands, much like Lauren was saying about the whole organization. There are also some safety concerns, because I hear that a lot of the homeless population have drug addictions and might not be in the greatest health." While she had some the same concerns, Maria was surprised by how direct the responses had been from Lauren and Omar. It was almost as if she was forcing their participation, rather than feeling a collaborative effort. But at least they were talking through a few ideas, and that alone, if for no other value, gave her a chance to understand her colleague's perspectives and values as they related to the mission.

As they left the meeting room and headed towards the lobby, they ran into someone that Lauren immediately recognized and made a beeline to speak with. As Maria caught up with her Lauren said:

"Hi Councilman Nguyen. Lauren Byers from the Orcas. We met at the Chamber Dinner a few months ago."

"Oh yes, how are you? Surprised to run into you here at the practice facility. I thought you were located at the main office," Councilman Nguyen said.

Lauren responded with, "Yes, that's right. I'm here today to meet with a member of the coaching staff on our homeless initiative you may have heard about. We'd like to see if we might be able to work with you on the tents idea the council is considering. We've just been discussing how important it is to try and make a difference in this local issue, and also 
work with the city council to make sure we manage community perceptions in the best way possible."

“Lauren, I couldn't agree more. I think it is so impressive that you and the Orcas are looking to help in this area, and I think you're right that it will be in both of our best interests to develop a plan that the local community can get behind. I wish you and your colleague here all the best, and look forward to working with you more on this initiative."

On the way out of the practice facility they ran into one of the star players arriving for practice. He called out to Omar with a big smile and gave him a high five into a handshake. Omar introduced Maria and Lauren to the player and they had a brief chat, then it was off to the parking garage and back to work. As they walked out of the doors, Maria noticed a crowd of fans who were roped off by security trying to get pictures and autographs from the players who were arriving for practice. Internally, she was basking with pride, reflecting on how special it was to be affiliated with an NBL team. She viewed herself as a 'fan on the inside' who could help make a difference for both the organization and the community.

\section{Maria's Frustration Builds}

Over the course of the next few months (October - November), Maria began to feel as if she was tasked with the impossible, as all the options considered were wrought with concern from either Lauren, Omar, or both. Maria knew that they usually were making very reasonable and impassioned arguments, however at the same time she felt like they were not meeting their call to provide recommended steps for the Orcas to engage with this important community issue. While it was never meant to be a top-secret venture, it was a little concerning how much Lauren and Omar had reached out to others for possible solutions, and sometimes to voice their concerns. Though Maria did not have a high need to be in charge in typical interpersonal dynamics, she was in this case, and didn't feel she was making much progress. She decided to meet with both Lauren and Omar individually to develop a bit more 
rapport with each, and to address some ground rules for information sharing and loyalty to the HOME task force and its stated objective. She had begun to feel pressure from senior leadership for not being further along in the overall initiative.

Around one month into the NBL season (late November), Maria noticed some differences in the organizational dynamics and with her interactions Lauren and Omar. The immediacy of the 'next game' seemed to have several employees more on edge all the time. There was excitement in the air before each home game, and a bit of relief when the team took off on an extended road trip. Engaging with employees during the season took on a different feel, and Maria had to learn by experience the best ways to do this. When she started her job, Maria felt like she had the full attention and efforts of Lauren and Omar, but that had certainly lessened as the regular season had gotten underway. This change had been most pronounced with Omar, who always seemed to be too busy to meet or engage with the task force as there was always something 'urgent' he needed to take care of after the last game, or prior to the next. When trying to schedule one meeting, Omar had actually gotten pretty aggressive with her on the phone the day after a tough loss, saying "Look Maria. I know it might be hard for you to understand, but we're going through some rough times at the moment, I just have more important things to do right now." With games every few days, it seemed like it was going to be a never-ending battle to get him to concentrate on the HOME initiative again. Lauren, coming from the banking world where day to day operations were not nearly as contingent on external factors (like team performance), was also becoming frustrated because of what appeared to be a lack of effort by some of the players during a recent losing streak. She told Maria “They just look like they're feeling sorry for themselves. Maybe we should require them to engage with this homeless initiative so they realize how fortunate they really are." 
Deep inside, Maria understood the challenges Lauren faces in her job, and didn't take offense: She knew that when the team loses it can often negatively influence many of the metrics she tracks and jeopardize the way her job performance is viewed. In this league, the organization's brand image is often influenced by a number of uncontrollable and external factors, and though Lauren had been working in sport for a while now, she still didn't seem to accept that part. Further, Lauren had missed several recent games because "it was too difficult for her to watch when the team was losing," and Maria figured this was part of the reason.

\section{Decision Time}

It is time for another called meeting. Maria is determined to make some real progress during the next in-person conversation she has with the group. She needs an update from Omar on his efforts to reach out to his league contacts for relevant ideas. She also needs Lauren to put forth a positive idea, rather than a litany of objections. Most importantly, she wants to move the needle and make some meaningful progress on what she was hired to do. Her next moves will no doubt have a major impact on the success or failure of the project. 


\section{Appendix}

Orcas Front Office Staff Profiles

Maria Martinez: Community Relations Assistant / Director of HOME Taskforce

What is your background?

"I'm 29 years old and have Mexican and American roots, but grew up in

Western Canada. I was a four-year member of the Grand State College

basketball team, and graduated with a major in communications and public

relations. Previously, I worked for three different charitable organizations and

spent a lot of time investing in local communities to build more livable spaces

for residents to enjoy."

What is the best thing about your job?

"I grew up in Western Canada and was always a big fan of the Orcas as a kid, and I have a passion for community development, so blending the two is a dream come true for me. Since leaving the area after high school, I have been a big fan of the Orcas organization for the way that they have used their platform to engage with important social issues and give back to the Osmington metropolitan area."

What is one of your professional goals?

"I'd like to eliminate homelessness. I have such a passion to solve this issue.

Everyday I come to work I think about it, and want to find a way for the great people of Osmington to join hands in the effort. Everybody should have a place to call home."

Omarmerhi (Omar) Simmons: Player Programs Director

What is your background? 
"I was born in Nigeria, lived there 8 years, then my family moved United States.

I played football and basketball at Northeast University and my best memory was playing in the Sugar Bowl and the NCAA tournament in the same year as a Senior."

What is the best thing about your job?

"To tell you the truth, when I was hired I was actually a big fan of [another NBL team] and it took me a while to join in the hoopla surrounding this organization. But now, I'm in. Totally in. I work with the players each and every day and get to see their amazing dedication as professionals and commitment to excellence, and that helps me create opportunities to support their personal, social, and professional development together with the aid of their wonderful families, agents, and other business associates."

What is one of your professional goals?

"Be more balanced. I spend so much time focused on the players, their needs, and with travel, that I often find I have little time for myself, or even some of the basic house cleaning things around the office."

\section{Lauren Byers: Marketing Director}

What is your background?

"I actually grew up in the Northeastern part of the United States, and my family was crazy about sports, especially ice hockey. Everyone I knew growing up played sports, except me, it just wasn't my thing. I worked in our family seafood restaurant all the way through college, and that's where I learned the meaning of hard work and good business. I attended Rubicon University and majored in marketing and sponsorship, then found a job as a marketing director at a small insurance firm in Boston. After two 
additional jobs in marketing departments for two different banks, I jumped at the chance to become the Marketing Director for the Orcas three years ago.

What is the best thing about your job?

"I love marketing. And for a marketing director, one of the best things (and the most challenging) is to be in an environment that is so filled with emotion. We have such passionate fans and wonderful corporate partners. I also love working for an organization who truly cares about the community they live in."

What is one of your professional goals?

"I'd like to help make the Orcas brand one of the most recognizable and communityoriented brands in the world. Personally, I also want to learn about Yoga. Sounds weird I know, but I've always wanted to tap into that side of me as a person." 